\title{
O Comitê Cidadão como estratégia cogestiva em uma pesquisa participativa no campo da saúde mental
}

\author{
The Citizen Committee as a co-management strategy \\ in participatory research in the field of mental health in Quebec
}

Eduardo Passos ${ }^{1}$

Thais Mikie de Carvalho Otanari ${ }^{2}$

Bruno Ferrari Emerich ${ }^{3}$

Lorena Guerini ${ }^{1}$

${ }^{1}$ Departamento de

Psicologia, Universidade

Federal Fluminense. Campus

do Gragoatá Bloco O/ 310,

São Domingos. 24.210-350

Rio de Janeiro RJ.

e.passos@superig.com.br

${ }^{2}$ Universidade de Montreal.

${ }^{3}$ Universidade Estadual de

Campinas.

\begin{abstract}
The theme of users' rights has become a central issue in contemporary debate on mental health. Drawing from the experiences of "Comitê Cidadão" (Citizen Committee), consisting of users and family members in an international research alliance between Brazil and Canada, an attempt is made to discuss the effects of the experience of co-management of the so-called Autonomous Medication Administration (GAM Gestão Autônoma da Medicação) participatory research project on these individuals. By means of a detailed description of the background of the Committee and interviews and analysis of the voice transcriptions of its members, the problems raised by the relation of dialogue between scientific knowledge and users' knowledge are examined in a methodological approach of participatory research. As a result of the research, it was established that the experience of the Citizens Committee in co-management of health research can be propitious to the increase in the degree of autonomy, greater empowerment and the exercise of leadership and citizenship, with the conse-
\end{abstract} quent emergence of subjects with rights.

Key words Rights, Citizenship, Empowerment, Autonomy, Participatory research
Resumo O tema dos direitos dos usuários ganha centralidade na discussão contemporânea no campo da saúde mental. A partir da criação de um Comitê Cidadão, composto por usuários e familiares em uma aliança de pesquisa internacional entre Brasil e Canadá, propomos discutir os efeitos, nestes sujeitos, da experiência de cogestão promovida pela pesquisa participativa "Gestão Autônoma da Medicação (GAM)". Através de descrição detalhada do histórico do Comitê e de entrevista e análise de transcrição da voz de seus membros, problematizamos a relação dialogada entre o saber científico e o saber advindo da experiência singular destes sujeitos, em uma perspectiva metodológica de pesquisa participativa. Como resultado da pesquisa, observamos que a experiência do Comitê Cidadão na cogestão da pesquisa em saúde pode ser propiciadora do aumento nos graus de autonomia, maior empoderamento $e$ exercício de protagonismo e cidadania, com a consequente emergência de sujeitos de direitos.

Palavras-chave Direitos, Cidadania, Empoderamento, Autonomia, Pesquisa participativa 


\section{Introdução}

A experiência apresentada neste artigo deriva da parceria Brasil/Canadá sob a chancela da Aliança Internacional de Pesquisa entre Universidade e Comunidade (ARUCI). A Aliança é um programa de subvenção do Conselho de Pesquisa em Ciências Humanas do Canadá (CRSH/SSHRCC) que visa desenvolver parcerias internacionais igualitárias entre universidade e atores da comunidade $^{1}$. No início de 2009 foi proposta a ARUCI Saúde Mental e Cidadania (ARUCI-SMC), com duração de cinco anos e que envolve parceria binacional entre colaboradores comunitários, da rede pública de saúde e assistência social e de universidades ${ }^{2}$. Tendo a participação de diferentes atores como base estruturante de seu programa, a Aliança trabalha com o aprimoramento das competências de seus membros - usuários dos serviços de Saúde Mental (SM), trabalhadores de saúde e universitários; possibilitando, assim, a produção de conhecimento calcado no encontro entre os saberes científico, prático e experiencial. Tal perspectiva participativa contribui para a superação, no campo da produção de conhecimento, da cisão entre esses atores, considerando que o diálogo entre eles pode promover a coconstrução de sujeitos e coletivos ${ }^{3}$.

Atualmente, a ARUCI-SMC se conforma em 240 membros e mais de 40 projetos. No Brasil, após três anos de seu início, a Aliança desenvolveu mais de 17 projetos em oito municípios dos estados de São Paulo, Rio de Janeiro, Rio Grande

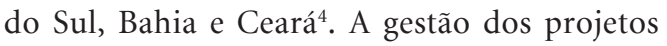
brasileiros é feita através de reuniões Multicêntricas que contam com a participação de docentes e discentes universitários, gestores e trabalhadores de serviços de saúde, além de usuários e familiares representantes dos locais nos quais tais experiências são desenvolvidas. A participação dos usuários e familiares - estes últimos sem direito a voto - se dá formalmente pelo Comitê Cidadão (CC), objeto de interesse neste artigo.

Entre as ações do CC, destacamos a participação na gestão e execução da Gestão Autônoma da Medicação (GAM), programa de pesquisa da ARUCI-SMC. Focalizaremos a aposta participativa que caracterizou a metodologia deste programa articulador dos dois países e que envolveu quase todos os centros da ARUCI-SMC brasileira. Iniciada antes mesmo do lançamento da Aliança no Brasil, a estratégia GAM oportunizou a parceria entre grupos de pesquisa do Brasil e Canadá, reunindo coletivos brasileiros que se identificavam com seus pressupostos ético-políticos ${ }^{5}$.
Originada no movimento comunitário de Quebec, a estratégia GAM teve início no final da década de 80 como uma abordagem em que o usuário, com seu saber fundado na experiência, está no centro das decisões de seu tratamento medicamentoso ${ }^{6}$. São princípios da GAM: a importância da qualidade de vida dos usuários; a retomada do poder contratual; o reconhecimento da pluralidade de significações da medicação; o respeito pela pessoa, suas decisões e seus direitos; a abordagem ampla do sofrimento e do bem estar $^{7}$. No Brasil, traduzimos e adaptamos, com metodologia participativa, o Meu Guia Pessoal da Gestão Autônoma da Medicação (GGAM), ferramenta construída no Quebec com a finalidade de promoção de protagonismo e autonomia dos usuários no que se refere à gestão dos psicofármacos. Avaliou-se os efeitos da experiência GAM com usuários, trabalhadores, familiares e residentes em SM e em Psiquiatria de diferentes universidades do país ${ }^{8}$ Realizada entre 2009 e 2011, a pesquisa foi financiada pelo CNPq e se deu em Centros de Atenção Psicossocial (CAPS), nas cidades de Campinas (SP), Rio de Janeiro (RJ) e Novo Hamburgo (RS).

Utilizando uma abordagem grupal, a estratégia GAM no Brasil favorece modos de cogestão, trabalhando coletivamente temas como cidadania e autonomia9. Neste artigo, além das atividades do CC relacionadas ao conjunto da ARUCI-SMC, tomaremos como base a adaptação do GGAM, considerando que o CC foi um elemento importante no desenvolvimento do instrumento GGAM brasileiro, estando presente em quase todas as etapas da pesquisa.

\section{A reforma psiquiátrica \\ e o desafio da participação cidadã}

No Brasil, o complexo processo reformista no campo da SM, desde seu início no final da década de 70, manteve-se em consonância com o processo de Reforma Sanitária que construiu as bases de nosso Sistema Único de Saúde (SUS) criando possibilidade para que a saúde se tornasse direito de todos e dever do Estado.

O que se propõe a partir das Reformas da Saúde é a consolidação de um processo de democratização participativa, mediante dispositivos que forcem os limites deste modelo, ampliando o direito dos usuários, que ganha sentido não só legal, como também experiencial. A questão de direito se torna de fato: vai-se da dimensão formal do direito ao seu exercício político, do direito como lei àquele como experiência sub- 
jetiva. Trata-se de recolocar a discussão sobre participação popular, criando uma nova cultura política que, ao democratizar as relações, ative o processo de construção do direito à saúde e à cidadania.

No contexto do SUS, a noção de cidadania não se confunde com o reconhecimento teórico de igualdade dos sujeitos, mas exige condições de existência comparáveis (equidade). Para cidadania plena, é preciso ter condições suficientes de inserção e participação social, através da troca recíproca entre indivíduo e coletividade. Para Clément $^{10}$, não é suficiente incluir os sujeitos se não há meios para a participação concreta na comunidade. Ser cidadão é tomar seu lugar em uma sociedade e contribuir para um projeto comum.

Em SM, a participação cidadã pressupõe a mediação das diferentes dimensões da Reforma Psiquiátrica ${ }^{11}$. É necessário considerar o usuário como protagonista e cogestor de sua vida (dimensão política), coautor do conhecimento em SM (dimensão epistemológica), sustentado por leis que o considerem em sua singularidade (dimensão jurídica), por práticas de inclusão no tecido social (dimensão sociocultural) e com acesso a serviços que contemplem o cuidado (dimensão técnico-assistencial) ${ }^{12}$

Desta forma, apontamos que o plano de gestão coletiva do cuidado pode ser experimentado a partir de duas perspectivas não excludentes: seja como experiência vivida frente a direitos já constituídos, seja como experiência de criação coletiva de autonomia e de modos de existência livres e cidadãos. Essa dupla perspectiva confere aos direitos dos usuários a dimensão desta experiência, para além da jurídico-política, o que ocorre através do engajamento dos sujeitos no plano comum em que compartilham a experiência de ter direitos e efetivam o pertencimento a um coletivo que os reconhece. Consideremos, então, uma "experiência de direitos" que emerge do processo a um só tempo de singularização e de coletivização que denominamos de autonomia coletiva.

Interessa-nos, a partir da reflexão acerca da participação nesta Aliança de Pesquisa, pensar a dinâmica coletiva que coproduz sujeitos da experiência de direitos, sejam eles pesquisadores ou usuários. Para tal, daremos destaque ao dispositivo de cogestão do CC enquanto catalisador de processos de subjetivação.

\section{Participação como método de pesquisa}

A participação dos sujeitos envolvidos na pesquisa é um modo de garantir seu protagonismo no processo de produção de conhecimento. Neste sentido, as pesquisas participativas e colaborativas possuem a capacidade de reunir os saberes e as competências dos diferentes atores (stakeholers), contribuindo para maior coerência entre os valores da pesquisa e da comunidade e oferecendo, desta forma, possibilidades de potencialização da capacidade de ambos. No campo da SM, os saberes que emergem dos processos de parcerias podem facilitar a adoção e a incorporação de novas abordagens, avançando em relação ao hiato entre os resultados das pesquisas clínicas e as práticas implantadas nos serviços ${ }^{13-16}$

Para isto, é primordial a participação de usuários, através de pesquisas baseadas nas experiências e nos insights desses atores específicos, para que eles possam colaborar tanto com a construção de perguntas, quanto no desenho de metodologias, nas análises e na disseminação dos resultados $^{17-19}$. Segundo Callard e Rose $\mathrm{e}^{17}$, este tipo de pesquisa se mostrou competente na explicitação dos desejos dos usuários em relação a abordagens e serviços, mostrando aquelas que funcionam, ou não, na melhoria de suas vidas. Além disto, elas puderam ajudar no avanço de orientações éticas de participação em pesquisas e sobre como estes estudos podem desenvolver evidências e teorias para a construção de prioridades políticas baseadas em diretrizes que buscam maior autonomia dos usuários, além de mais participação nos espaços sociais, econômicos e políticos e na ampliação de transformações sociais mais amplas, especialmente em relação aos desafios do estigma e da exclusão social.

No Brasil, embora escassas, diferentes experiências de participação de usuários têm sido publicadas, sendo aqui enfatizadas as que consideram suas vozes na avaliação de ações e serviços de $\mathrm{SM}^{20,21}$ e na produção de importantes instrumentos para a garantia de direitos, por meio de guias $^{22,23}$.

Do lugar de meros informantes, os participantes são incluídos na pesquisa assumindo posição ao lado do pesquisador, o que altera significativamente a maneira de organizar os procedimentos, muitas vezes caracterizados pela hierarquia dos diferentes e pelo corporativismo dos iguais. O desafio é o de transformar a pesquisa sobre em uma com sujeitos.

Tradicionalmente usuários e trabalhadores dos serviços de saúde são chamados a participar de pesquisas através de grupos focais, de questionários ou de entrevistas que "coletam" o material bruto para o trabalho de organização e análise a ser realizado pelos pesquisadores. Quem pesqui- 
sa e aqueles que são pesquisados ocupam posições marcadamente distintas e separadas no processo de investigação ${ }^{24}$.

Quando realizamos pesquisa com humanos, este que ocupa a posição de objeto não só se coloca como obstáculo à investigação - o objectus, em latim, "ação de se pôr adiante", tal como um obstáculo a ser dominado - mas é participante ou sujeito da pesquisa - o subjectus que designa “o vizinho, o próximo, o limítrofe". Neste sentido, para realizar uma pesquisa com sujeitos, colocando lado a lado pesquisador e pesquisado, é necessário um método de tríplice inclusão. A primeira é a que coloca lado a lado os diferentes sujeitos implicados na produção do conhecimento. Há, no entanto, consequências do primeiro procedimento, pois ele faz aparecer as tensões geradas pela não hierarquização da diferença entre os grupos de interesse da pesquisa. O engajamento dos diferentes sujeitos implicados no processo de pesquisa não só gera interesse e cuidado, mas também põe em análise, frequentemente, as crenças e os pressupostos do pesquisador. Afirmar o protagonismo do objeto nos força, portanto, a incluir os efeitos críticos ou os analisadores da pesquisa que emergem da colocação lado a lado do pesquisador e dos participantes, o que caracteriza o segundo nível da inclusão. Por fim, somos conduzidos ao terceiro nível: a pesquisa se efetiva como participativa na medida em que produz uma experiência coletiva ao contrair os diferentes sujeitos em sua diferença em uma experiência de grupalidade com autonomia coletiva. A tríplice inclusão se realiza finalmente com a valorização dos movimentos do coletivo que são ativados e legitimados a partir da lateralidade e da inclusão dos analisadores da pesquisa. Temos, então, três níveis de inclusão a dos diferentes sujeitos; a dos analisadores da pesquisa; e a dos movimentos do coletivo - a que correspondem três procedimentos: lateralização; análise dos pressupostos e crenças da pesquisa; contração do coletivo autônomo.

A tríplice inclusão é uma orientação metodológica para a pesquisa participativa em saúde. Não pressupõe homogeneização dos participantes, pois os usuários, familiares e trabalhadores se tornam pesquisadores ao lado dos pesquisadores universitários, mas se mantém a diferença de inserção de cada um no contexto da investigação.

Como manter a diferença sem hierarquizála? Como fazer cogestão da pesquisa? A manutenção da diferença - em se tratando da diferença por tanto tempo estigmatizante - leva muitas vezes a provocar reação por partes dos usuários que sinalizam os perigos sociais oriundos dessa diferença. Em nossa aposta na metodologia participativa, tomamos as reações dos usuários como analisadores sociais que nos ajudaram a realizar o trabalho de análise a que a investigação se propõe.

\section{Empowerment e autonomia}

Em uma sociedade marcada pela hierarquia e desigualdade, os segmentos minoritários precisam lutar para garantir condições mínimas de direitos sociais. Fundadas como uma resposta dos próprios usuários aos efeitos iatrogênicos do paradigma hegemônico, as práticas de empoderamento indicam processos de transformação social na $\mathrm{SM}^{25}$. Vasconcelos ${ }^{26}$ define empowerment como aumento do poder e autonomia pessoal e coletiva de indivíduos e grupos sociais submetidos a relações de opressão, dominação e discriminação social.

Tal conceito tem sido empregado atualmente na SM para pensar a participação social e a defesa dos direitos de cidadania. As pesquisas em saúde que o adotam apontam, em suas metodologias, para a importância ética e política de incluir sujeitos e grupos valorizando processos de empoderamento ${ }^{27}$, o que favorece a construção de ações mais democráticas e inclusivas ${ }^{28}$ em um movimento de construção conjunta de sujeitos e coletivos autônomos ${ }^{29}$. A autonomia não é contrária à dependência, sendo efeito de processos de coconstituição de sujeitos que agem sobre si mesmos e sobre o contexto conforme objetivos democráticos.

Assim, a construção de autonomia coletiva não se reduz à explicitação das diferenças e à criação de consensos. Implica em negociação entre saberes e visões de mundo dos profissionais e de usuários, incluindo a rede de relações que os cerca. Depende de condições democráticas e do funcionamento efetivo das políticas públicas, assim como do acesso dos sujeitos à informação e da capacidade crítica acerca desta. É fenômeno complexo que não pode ser visto como dado independentemente do contexto que envolve a experiência vivida junto ao coletivo. Construir processos de autonomização é uma direção do tratamento em SM, pressupondo a gestão compartilhada do cuidado e a valorização do direito dos usuários e, mais amplamente, dos direitos humanos.

Vasconcelos nos alerta para os riscos de cooptação da estratégia participativa, frequentemente "aparelhada" seja por partidos políticos, seja pela própria organização hierarquizada dos conselhos de saúde. Acreditamos que a produ- 
ção de novas práticas de cuidado em saúde e a mudança nos modelos de atenção e gestão do SUS dependem da aposta na criação de políticas públicas propulsoras de transformações nessa paradoxal relação com o Estado. Desse modo, entendemos que práticas cogestivas por dentro da máquina do Estado podem forçar os limites dessa tendência à interiorização que leva ao aparelhamento da participação cidadã ${ }^{30}$.

O modo de operar do CC da ARUCI-SMC nos leva a crer que é através do coletivo cogestivo que podemos inverter a tendência à interiorização e aparelhamento, em direção à construção de políticas públicas e à produção de conhecimentos que se orientem pelos princípios democráticos da Reforma Sanitária, da Reforma Psiquiátrica Brasileira e da Luta Antimanicomial.

É possível experimentar formas mais democráticas e coletivas de vida, através de práticas de si que investem na capacidade de auto-organização ${ }^{31}$ e que se sintonizam com o ideário democrático do SUS no enfrentamento da precariedade e vulnerabilidade social ${ }^{32}$.

\section{Comitê cidadão - histórico e objetivos}

O CC é o dispositivo concebido pelo desenho da ARUCI-SMC que efetiva a gestão participativa da Aliança e de seus projetos. Tem por mandato "assegurar o respeito e a participação ativa das pessoas que vivem ou já viveram com problemas de saúde mental nas diferentes instancias e atividades e permitir-lhes participar mais amplamente das diretrizes da ARUCI-SMC"33.

O termo "cidadão" que qualifica o comitê foi escolhido e reivindicado por seus próprios membros, indicando o foco escolhido para orientar suas reflexões e contribuições. Não se trata apenas de participação dos usuários e familiares, mas de participação-cidadã. Sua composição aponta para a aposta política de desnaturalizar as práticas e os papéis construídos historicamente, seja do pesquisador que tem a verdade sobre o objeto pesquisado ou do "louco" que participa de modo silenciado como objeto da pesquisa. (Figura 1).

No Brasil, o CC é constituído por nove integrantes, eleitos em assembleia e representantes dos três estados com maior concentração de projetos: São Paulo, Rio de Janeiro e Rio Grande do Sul.

\section{As ações do comitê cidadão}

A participação cidadã na pesquisa realiza-se de duas formas: através do CC e por participações individuais que ocorrem em atividades de pesquisas locais, o que garante uma parceria sólida entre universidade e comunidade (Figura 2).

Como ator coletivo, o CC esteve presente em todas as reuniões multicêntricas e videoconferências Brasil/Canadá, principal espaço de reflexão e gestão da pesquisa GAM e da ARUCI-SMC, ora assumindo papel de consultor, ora tomando decisões. Durante os três anos iniciais da Aliança no Brasil, tais encontros aconteceram, em média, a cada dois meses, revezando-se entre os três estados de maior concentração de projetos. Tal dinâmica permitiu aos membros do CC visitas a diferentes municípios e serviços da rede de SM. Muitos viajaram em avião pela primeira vez, assim como entraram nos espaços das universidades e fizeram encontros internacionais com membros da ARUCI-SMC canadense. Um dos membros do comitê iniciou curso de inglês motivado pela experiência desses encontros.

Em uma de suas tarefas principais na Aliança, o CC constitui-se como comissão avaliadora de projetos independentes financiados pela ARUCISMC. Em 2010, a ARUCI-SMC no Brasil lançou um edital no qual cinco ações desenvolvidas por diversos atores da comunidade foram contempladas com um financiamento de até $\mathrm{R} \$ 10.000,00$ cada. A escolha dos contemplados foi feita por dois comitês: o Comitê Científico, constituído por professores e pesquisadores do campo, e o CC. Coube ao CC Cidadão construir os critérios utilizados para a avaliação dos projetos. Entre tais critérios, considerou-se a pertinência em relação aos eixos da ARUCI-SMC (pesquisa, formação e transferência de conhecimento) e a importância da ação que demandava financiamento para o usuário, para a comunidade e para o serviço. Este foi um momento-chave para a consolidação da Aliança, em que a participação de usuários e familiares foi fundamental para a articulação entre os saberes acadêmico e da experiência cidadã. Além disso, o CC realizou reuniões fechadas em que discutiram, entre outros assuntos, identidade e função do comitê, processos de trabalho e realizaram trocas sobre os contextos políticos das redes locais de serviços em SM.

Em um dado momento do programa, o próprio comitê refletiu e reivindicou sua condição de colaborador técnico. Propuseram contrapartida financeira para a participação de seus membros, igualando suas expertises àquelas dos acadêmicos que eram remunerados através de bolsas de estudo e salários. Tal demanda foi entendida como um avanço na constituição da identidade cidadã do CC que assumia seu protagonismo na luta por direitos, inclusive dentro do espaço da 


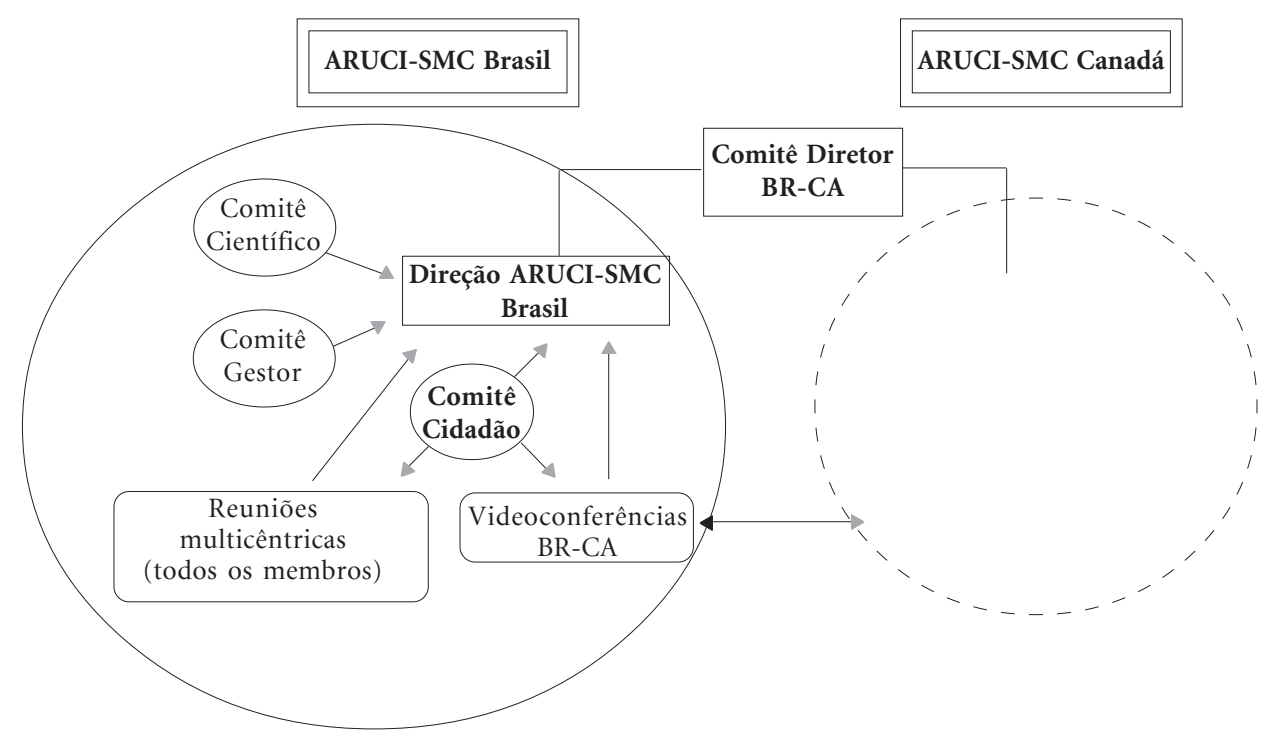

Figura 1. Descrição de estrutura de gestão ARUCI-SMC Brasil².

*Comitê Cidadão: composto por nove membros com direito a voto, todos usuários de serviços de SM. Conta, ainda, com a participação de familiares; Comitê Científico: possui função consultiva. Composto por experts de campo, ele é convocado a participar de atividades específicas e pontuais, como avaliação de projetos de pesquisa; Comitê Gestor: possui função de orientação, planejamento e avaliação. É composto por representantes de diferentes categorias (pesquisadores, usuários, familiares e profissionais). Seus membros participam de forma ativa das Reuniões multicêntricas e Videoconferências; Reuniões multicêntricas: espaço de participação aberta a todos os membros da ARUCI-SMC BR. Tem como característica coordenar os projetos de pesquisa e convergir as diferentes linhas teóricas, incluindo a perspectiva dos membros da comunidade; Videoconferências: espaço de encontro entre TODOS os membros da ARUCI-SMC, ocorre, ao menos, duas vezes por ano.

Direção ARUCK-SMC BR: composta por pesquisador diretor e por usuário diretor.

Comitê Diretor BR-CA: reúne a direção dos dois países e dirige a ARUCI-SMC.

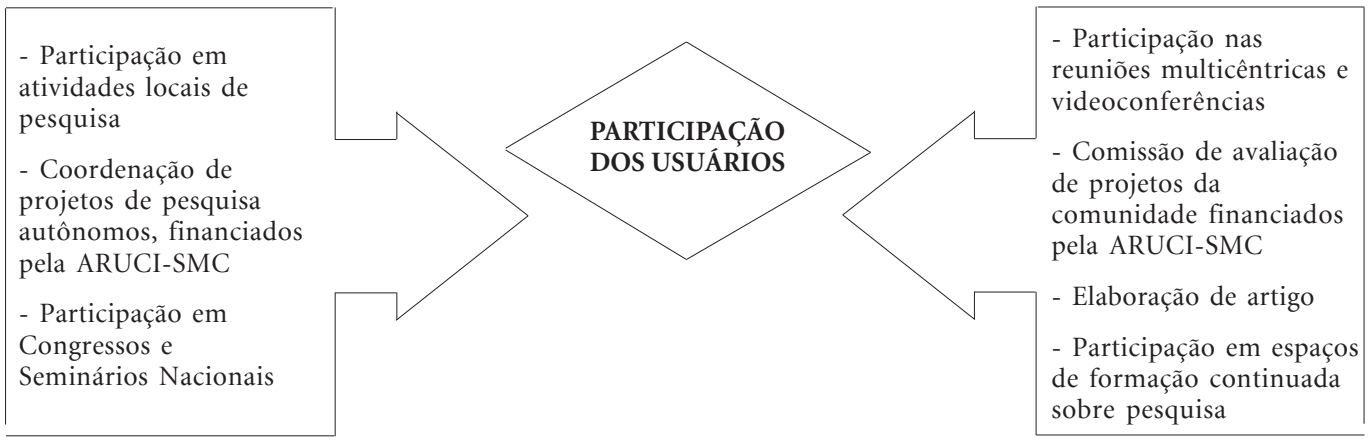

CIDADÃO

COMITÊ CIDADÃO

Figura 2. Dinâmica da participação dos usuários na ARUCI-SMC.

"No caso de Campinas, tem-se uma parceria singular com a Associação Florescendo a vida de Usuários, Familiares e Trabalhadores da Saúde Mental/AFLORE, formalizada por contrato institucionais, em que a associação recebe um financiamento anual. Tal parceria foi idealizada ainda na etapa de planejamento da Aliança, entendendo-se que a associação era o ator que representava os usuários em Campinas, município sede da ARUCI-SMC. Como contrapartida, os membros da AFLORE devem estar próximos de algumas das atividades de pesquisas da Aliança, sendo que o presidente da associação é também um dos diretores da ARUCI-SMC Brasil. 
pesquisa. Naquele momento, a maioria dos membros do comitê não estava formalmente empregada, sendo que apenas alguns contavam com alguma forma de benefício ou aposentadoria. A retribuição financeira da pesquisa, mesmo que baixa, contribuía para o avanço da reinserção social através da atividade laboral.

Os encontros do CC também incluíram atividades de formação em informática e outros temas considerados relativos à academia. Um exemplo importante é o artigo produzido coletivamente e encaminhado para o Caderno HumanizaSUS do Ministério da Saúde, sobre a experiência do encontro entre universitários e membros da comunidade, na pesquisa $\mathrm{GAM}^{34}$.

Individualmente, seus membros participaram de encontros com os grupos de pesquisa locais, participaram de colóquios e congressos nacionais e coordenaram dois projetos de pesquisa, planejados e executados a partir de suas experiências como militantes da SM. Em um, desenvolveu-se o Guia dos Usuários da Saúde Mental (GUSM), metodologia que procura trazer para usuários de CAPS, reflexões acerca de seu tratamento, da rede de serviços, do controle social e dos direitos em $\mathrm{SM}^{35}$. O outro projeto propõe grupos que utilizam a estratégia GAM, em que os facilitadores são usuários do serviço de $\mathrm{SM}^{36}$.

Assim, entendemos a experiência no CC como promoção de cidadania, na medida em que instrumentaliza os usuários para o posicionamento político. Como espaço de formação técnico-científica, o CC favorece o contato com o fazer científico contribuindo para a experiência distribuída do modo investigativo da ciência, que permite um olhar crítico sobre o mundo e a criação de um espaço político de emancipação ${ }^{37}$.

A experiência de lateralização cogestiva na pesquisa permitiu aparecer diferentes experiências de pesquisador: pesquisador universitário ao lado de pesquisadores usuários e pesquisadores familiares.

Todos nós já vivenciamos alguma experiência de trabalho em parceria entre universidade e usuários dos serviços. Mas foi algo inédito, para nós, a abertura das tarefas próprias ao mundo acadêmico, como a pesquisa, o desenho de projetos e a produção de artigos. Experimentamos e percebemos como e o quanto as questões que nós colocamos tem clara relação com a nossa inserção institucional e social. Esta aliança entre acadêmicos e usuários propiciou o surgimento de novas ideias e modos de trabalhar, abriu-nos novos horizontes, de tal modo que não conseguimos mais imaginar o trabalho sem estarmos uns e outros juntos ${ }^{34}$.
Como efeito deste processo de participação, o protagonismo tende a ser estendido a outros aspectos da vida. Nesse caso de participação na gestão de pesquisa, verificamos a estimulação de cidadania como possibilidade de reconhecer-se enquanto sujeito capaz de produzir a si mesmo na experiência coletiva (autonomia coletiva), modificando seu ambiente.

\section{A fala cidadã}

Na última reunião Multicêntrica do ano de 2012, realizamos uma entrevista coletiva com o CC a fim de validar nosso ponto de vista acerca do processo participativo. Propusemos uma avaliação da participação nos diversos projetos em que o CC está envolvido, a partir de algumas perguntas que lançamos durante uma reunião desse coletivo. Destacaremos as questões que se referem ao problema da participação e dos direitos na pesquisa GAM, confrontando nossas análises com os relatos dos membros do CC.

A pauta dessa reunião era composta, dentre outros pontos, pela avaliação da participação do CC na ARUCI-SMC/GAM. Já no início da reunião, os membros do comitê se mostravam comprometidos com cada etapa de desenvolvimento da pesquisa, até mesmo no que se refere às suas questões burocráticas. Um usuário dizia: se a gente quer politicas públicas decentes e humanizadas a gente também tem que prezar pela verba, enquanto outro enfatizava que o cidadão tem que prestar contas pro cidadão.

A primeira pergunta que fizemos ao grupo interrogava a qualidade de sua participação nos três principais espaços existentes na ARUCI/SMC (Videoconferências, Multicêntricas e CC). Um usuário responde: Aqui nesse grupo me sinto porta-voz também, porque como S. falou e N., nós aqui sugerimos ideias, reivindicamos, lemos nossa bula, muita coisa, assim de autonomia, nossa mesmo, de empoderamento como diz o J., eu fico muito feliz hoje! Daqui a pouco nós vamos para a multicêntrica, para a videoconferência, pô, quem disse que um paciente psiquiátrico poderia estar em uma situação dessa assim? Num ambiente desses? Isso é uma revolução da saúde mental para nós, um enriquecimento muito grande [...] Não é fácil viver assim, né L? Doença mental não tem cura, mas tem controle. Há dez anos eu estou assim, há dez, entre aspas, controlado. Hoje eu escuto uma voz por aqui, saí por aqui, eu não tô ligando. Não pego pra mim mais as coisas, sabe? Eu me sinto um porta-voz, às vezes, dos que ficaram muitos anos nos manicômios e não tiveram como falar. Morreram 
confinados no manicômio. Olha o nosso amigo R., ficou muitos anos no manicômio. Hoje ele consegue falar, fala o nome dele. Hoje ele consegue falar direitinho, tudo. Isso que é Reforma Psiquiátrica! Outro usuário intervém dizendo: As vozes, a gente pega e faz um coral com elas! (Risos).

A segunda pergunta que introduzimos na reunião do CC questionou a relação dos usuários e familiares com os outros grupos de interesse que compõem a pesquisa, como, por exemplo, os profissionais da saúde e os pesquisadores. Gostaríamos de saber como a fala dos membros do CC é acolhida no grupo heterogêneo que participa das reuniões multicêntricas, por exemplo. Um usuário responde: Foi passado para nós o que se pensava lá no Canadá. Só que nós, quando começamos a discutir, nós entendemos direitinho a voz de lá. Porque aí eles lá estavam falando a nossa voz. Aí, quando nós começamos a entender, os pesquisadores perguntaram: 'E agora como que nós vamos fazer? Tem que chamar eles pra mesa e começar a criar a teoria. Hoje, o que você vê fomos nós que criamos! [...] Então quando você lê o GAM, fomos nós que criamos! [...] Não é fácil romper com essa tradição, essa tradição ainda tá aí, a gente ainda vê isso! Quando a gente viajou para Assembleia eu ouvi uma pessoa dizer: 'Mas será que ele é louco?' Porque estão acostumadas a ver o louco de papel! Estão acostumadas a ver o louco drogado! Estão acostumadas a ver o louco babão! Estão acostumadas a ver o louco desmaiando! Quebrando tudo! E não está acostumada a ver o louco falando, de si mesmo, de conhecimento. Uma usuária também traz sua experiência: Eu acho muito importante minha participação nas reuniões de vocês porque eu tive que parar de estudar na quinta série, perdi meu pai com sete anos, e eu sempre tive assim fascínio para estudar, me formar assim em alguma coisa na vida, sabe? E já que eu não pude fazer isso, infelizmente, não tive dinheiro dos meus pais, daí conviver com vocês assim, uns já são formados, outros estão estudando, eu gosto muito de conviver com as pessoas assim, sabe? E os pacientes também. Eu acho que, onde a gente vê a verdadeira amizade, é nos grupos. Outro usuário acrescenta: A gente cria vínculos de amizade e também é um lugar de empoderamento, onde nós somos ouvidos. Eu vejo isso aqui como uma coisa positiva, como um lugar de crescimento que tem uma proposta boa de melhorar a vida dos usuários de Saúde Mental [...] um lugar onde nós temos vozes.

A terceira pergunta introduzida buscava entender se os membros do CC sentiam-se pesquisadores. Um usuário responde: Eu nem me sinto como pesquisador e sinto como pesquisador. Por que eu não me sinto um pesquisador? Porque eu sinto uma certa liberdade. O pesquisador, ele é muito preso na academia, nas correntes, então eu não sou preso a isso, eu tenho uma certa liberdade, de fuçar, de olhar, de ouvir, falar sem compromisso. Essa é a diferença de ser ou não ser um pesquisador. Além das perguntas que levamos, o grupo discutiu bastante a experiência de escrita coletiva do artigo: $E u$ tenho o rascunho do artigo e eu me emocionei muito, com todos os textos que cada um escreveu, com cada fala que cada um escreveu. Tem tudo a ver com todos nós. Então ali tá um pouquinho de cada um de nós, mas resumindo, tá todos ali juntos! Eu acho isso muito importante e muito bonito, sabe? E eu acho também que o GAM mostrou uma forma para nós de ter fala, que a gente pode falar mais, não só dentro dos CAPS, ficar só dentro lá. Isso mostrou para nós que a gente pode ter autonomia, cidadania também, mostrou isso. E isso me reforçou muito, me deu um conhecimento pessoal muito grande, e a gente fez muitos amigos aqui dentro, né? No início eu lembro, a gente falava muito de medo de debater com o médico sobre a medicação, medo de falar: 'ah, esse remédio não tá me fazendo bem, será que não dá pra trocar?' Ou: 'será que depois que eu ficar melhor não dá pra reduzir?’ Essas coisas assim, isso tudo melhorou pra gente. E outra coisa é que o GAM, a gente sente dentro da gente, eu acho que, como eu falei ontem, isso poderia ser passado para as redes públicas, nas UBS também, né? Eaté a gente, nós próprios usuários, poderíamos fazer grupos falando nos CAPS ou outras redes públicas, para nós conseguirmos ajudar outros usuários que não estão bem, fazermos grupos assim, né? Eu acho isso muito importante.

A mesma usuária ainda acrescenta: Uma coisa muito importante é que os acadêmicos têm uma forma diferente de escrever [...] mas nem todos sabem o que significa aquela palavra, o que está na frase. Então, o que foi que a gente começou a questionar: 'porque não colocar um sinônimo, quando é uma coisa muito assim que a gente nunca ouviu falar?' Porque Psicologia tem muita coisa que a gente não sabe, né? Então, houve várias vezes que a gente mudou o artigo, a gente debateu muito sobre isso, né G.? E muitas vezes não era a nossa fala que estava ali; então isso foi indo, foi feito um artigo, daí depois foi feito outro, daí o terceiro já foi mudado completamente. A gente nem conhecia mais o artigo, né? Então no quarto, já começou a melhorar. Aí no quinto, estava ótimo. Foi encerrado assim, todo mundo entendeu, né? Então, para as palavras mais difíceis, o sinônimo foi colocado. E foi colocado lá embaixo no rodapé explicando ainda o que significa essas palavras mais difíceis. En- 
tão, para nós, foi muito bom. E que nem eu disse, não vai ser só acadêmicos e usuários que vão ler esse livro, domésticas, garis, todos podem ler! Médicos! Então todos têm que entender!

Além da experiência do artigo, os usuários também conversaram sobre o desejo de continuar construindo e ampliando o projeto GAM: A gente tem que pensar na sequência no Brasil do GAM do ARUC, no interesse nosso. É a lição que fica. Não é uma coisa que veio do Canadá, mas uma coisa que vai ficar aqui. Como é que nós vamos construir isso dentro, junto com a sociedade? Não basta estar só aqui dentro da Universidade. A sociedade tem que saber isso!

\section{Conclusão}

Os desafios colocados pela Reforma Psiquiátrica e pelo SUS impõem que alteremos não só as práticas de atenção e gestão do trabalho na saúde, pois no campo da produção de conhecimento não podemos estar aquém da aposta democratizante das políticas públicas de saúde. Nesse sentido, é preciso equiparar nossas metodologias de pesquisa com a diretriz inclusiva e participativa

\section{Colaboradores}

E Passos, TMC Otanari, B Emerich e L Guerini participaram igualmente nas diferentes etapas de elaboração do texto.

\section{Agradecimentos}

À Paula B. Schaeppi pela colaboração na entrevista realizada com o CC e aos cidadãos que participam do Comitê: Amauri Nogueira, Elizabeth Sabino dos Santos, Fernando Medeiros, Júlio César dos Santos Andrade, Larry Fernando Diedrich, Luciano Marques Lira, Maria Regina do Nascimento, Nilson Souza do Nascimento, Renato Félix Ferreira de Oliveira, Roberto do Nascimento e Sandra Maria Schmitz Hoff. de modo a que o direito dos usuários ganhe importância e efetividade não só no contexto dos serviços de saúde como também nas práticas de pesquisa em SM. A pesquisa participativa que realizamos para a adaptação à realidade brasileira do GGAM nos permitiu avaliar as vantagens de um dispositivo de cogestão da pesquisa como o CC da ARUCI-SMC. A fala dos usuários integrantes do comitê nos indicou o protagonismo desses sujeitos e a sua inclusão como participantes corresponsáveis pelo processo de produção de conhecimento em SM. A experiência de lateralização na pesquisa reposicionou usuários, familiares, trabalhadores e pesquisadores da universidade na direção de práticas cidadãs e de reconhecimento de sujeitos de direitos. O saber científico e o saber produzido na experiência singular dos usuários e familiares em SM se entrecruzaram ampliando a capacidade de análise dos dados da pesquisa. Como resultado da pesquisa, observamos que a experiência da cogestão da medicação em saúde mental pode ser propiciadora do aumento nos graus de autonomia, maior empoderamento e exercício de protagonismo e cidadania, com a consequente emergência de sujeitos de direitos.

\section{Referências}

1. Conseil de recherches en sciences humaines. [Documento da Internet]. [acessado em 2012 out 12]. Disponível em: http://www.sshrccrsh.gc.ca/fundingfinancement/programs-programmes/cura-arucfra.aspx

2. Saúde mental e cidadania. Aliança internacional universidades - comunidades. Acontecimentos e novidades. [Documento da Internet]. [acessado em 2012 out 12]. Disponível em: http://www.arucismc.org/pt/

3. Campos GWS. Um método para a análise e co-gestão de coletivos: a constituição do sujeito, a produção do valor de uso e a democracia em instituições : o método da roda. São Paulo: Hucitec; 2000.

4. Saúde mental e cidadania. Aliança internacional universidades - comunidades. Projetos. [Documento da Internet]. [acessado em 2012 out 12]. Disponível em: http://www.aruci-smc.org/pt/projetos/

5. Onocko Campos R, Palombini A, Silva AE, Passos E, Leal E, Serpa O, Marques CC, Gonçalves LL, Santos DVD, Surjus LT, Arantes RL, Emerich B, Otanari TMC, Stefanello S. Adaptação multicêntrica de um Guia para a Gestão Autônoma da medicação. Interface (Botucatu) 2012; 16(43):967-980.

6. del Barrio LR, Poirel ML. Émergence d'espaces de parole et d'action autour de l'utilisation de psychotropes: la Gestion autonome des médicaments de l'âme. Nouvelles pratiques sociales 2007; 19(2):111-127. 
7. Regroupement des ressources alternatives en santé Mentale Du quèbec. Équipe de recherche et d'action en santé Mentale Et culture (RRASMQÉRASME). Repères pour une gestion autonome de la médication en santé mentale: guide D'accompagnement. Montreal: RRASMQ-ÉRASME; 2006.

8. Otanari TMC, Leal E, Onocko Campos R, Palombini A, Passos E. Os efeitos na formação de residentes de psiquiatria ao experimentarem grupos GAM. Rev. Bras. educ. med. 2011; 35(4):460-467.

9. Melo JJ, Schaeppi PB, Soares G, Passos E. Acesso e compartilhamento da experiência na gestão autônoma da medicação: o manejo cogestivo. Caderno HumanizaSUS. No prelo 2013.

10. Clément M. Partir de l'exclusion pour penser la citoyenneté: les enjeux du droit, de la participation et de la reconnaissance. Le partenaire 2008; 17(1):5-9.

11. Amarante P. A (clínica) e a Reforma Psiquiátrica. In: Amarante P, organizador. Archivos de saúde mental e atenção psicossocial. Rio de Janeiro: Editora Nau; 2003. p. 45-66.

12. Yasui S. Rupturas e encontros: desafios da reforma psiquiátrica brasileira [tese]. Rio de Janeiro: Escola Nacional de Saúde Pública; 2006.

13. Alegría M, Wong Y, Mulvaney-Day N, Nillni A, Proctor E, Nickel M, Wells KB. Community-based partnered research: new directions in mental health services research. Ethn Dis 2011; 21(Supl. 3):S1-8-16.

14. Horsfall J, Cleary M, Hunt GE. Developing partnerships in mental health to bridge the research-practitioner gap. Perspect Psychiatr Care 2011; 47(1):6-12.

15. Lindamer L A, Lebowitz B, Hough RL, Garcia P, Agurre A, Halpain MC, Depp, C, Jeste DV. Establishing an implementation network: Lessons learned from community-based participatory research. Implement Sci 2009; 4:17.

16. Wells K, Miranda J, Bruce ML, Alegria M, Wallerstein N. Bridging community intervention and mental health services research. Am J Psychiatry 2004; 161(6):955-963.

17. Callard F, Rose D. The mental health strategy for Europe: Why service user leadership in research is indispensable. J Ment Health 2012; 21(3):219-226.

18. Rose D. Collaborative research between users and professionals: peaks and pitfalls. Psychiatric Bulletin 2003: 27(11):404-406.

19. Staley K, Kabir T, Szmukler G. Service users as collaborators in mental health research: less stick, more carrot. Psychol Med 2013; 43(6):1121-1125.

20. Surjus LTLS, Onocko Campos R. A avaliação dos usuários sobre os Centros de Atenção Psicossocial (CAPS) de Campinas, SP. Rev. latinoam. psicopatol. fundam. 2011; 14(1):122-133.

21. Onocko Campos RT, Furtado JP, Miranda L, Ferrer Passos E, Gama CAP. Avaliação da rede de centros de atenção psicossocial: entre a saúde coletiva e a saúde mental. Rev Saude Publica 2009; 43(1):16-22.

22. Presotto RF. Participação de Usuários de Serviços de Saúde Mental em Pesquisas: Um olhar a partir dos conceitos de Empowerment e Recovery. Campinas: Universidade Estadual de Campinas; 2013.

23. Ludmila CC. Guia de direitos humanos loucura cidadã. Salvador: AMEA; 2011.

24. Onocko Campos R, Furtado JP, Passos E, Benevides R, organizadores. Pesquisa avaliativa em saúde mental. Desenho participativo e efeitos da narratividade. Campinas: Hucitec; 2008.
25. Bossé YL. De l'“habilitation" au "pouvoir d'agir": vers une appréhension plus circonscrite de la notion d'empowerment. Nouvelles pratiques sociales 2003; 16(2):30-51.

26. Vasconcelos EM. O poder que brota da dor e da opressão: empowerment, sua história, teorias e estratégias. São Paulo: Paulus; 2003.

27. Perkins DD, Zimmerman MA. Empowerment theory, research, and application. Am J community psychol 1995; 23(5):569-580.

28. Carvalho SR. Os múltiplos sentidos da categoria "empowerment" no projeto de Promoção à Saúde. Cad Saude Publica 2004; 20(4):1088-1095.

29. Onocko Campos R, Campos GSW. Co-construção de autonomia: o sujeito em questão. In: Campos GWS, Minayo MCS, Akerman M, Drumond Júnior M, Carvalho YM, organizadores. Tratado de saúde coletiva. São Paulo, Rio de Janeiro: Hucitec, Fiocruz; 2006. p. 669-688.

30. Benevides R, Passos E. A humanização como dimensão pública das políticas de saúde. Cien Saude Colet 2005; 10(3):315-325.

31. Passos E, Benevides R. Clínica e biopolítica na experiência do contemporâneo. Psicol. clín 2001; 13(1):8999.

32. Gama CAP. Saúde mental na atenção básica: as relações entre a subjetividade e o território [tese]. Campinas: Universidade Estadual de Campinas; 2011.

33. Saúde mental e cidadania. Aliança internacional universidades - comunidades. Brasil-Canadá. Comitê cidadão. [página na Internet]. [acessado 2012 dez 14]. Disponível em: http://www.aruci-smc.org/ pt/apresentacao/governanca/comite-citoyen/

34. Flores AA, Muhammad AH, Conceição AP, Nogueira A, Palombini AL, Marques CC, Passos E, Santos ES, Medeiros F, Souza GS, Melo J, Andrade JCS, Diedrich LF, Gonçalves LLM, Surjus LTLS, Lira LM, Xavier MAS, Nascimento MR, Silveira M, Nascimento NS, Ost PR, Oliveira RF, Nascimento R, Presotto RF, Hoff SMS, Campos RO, Otanari TMC.. A experiência de produção de saber no encontro entre pesquisadores e usuários de serviços públicos de saúde mental: a construção do Guia Gam brasileiro. Caderno HumanizaSUS. No prelo 2013.

35. Saúde mental e cidadania. Aliança internacional universidades - comunidades. Brasil-Canadá. Guia do usuário da saúde mental (GUSM). [página na Internet]. [acessado $2012 \mathrm{dec}$ 14]. Disponível em: http://www.aruci-smc.org/pt/projetos/as-praticascidadas-eixo-3/user-guide-for-mental-health-gusm/

36. Saúde mental e cidadania. Aliança internacional universidades - comunidades. Brasil-Canadá. Conquista de cidadania: como se constrói a participação? [página na Internet]. [acessado $2012 \mathrm{dec} 14]$. Disponível em: http://www.aruci-smc.org/pt/projetos/ as-praticas-cidadas-eixo-3/conquest-of-citizenshiphow-to-build-participation/

37. Demo P. Pesquisa: princípio científico e educativo. São Paulo: Cortez; 2001.

Artigo apresentado em 22/04/2013

Aprovado em 28/05/2013

Versão final apresentada em 05/06/2013 